\title{
Ditos acadêmicos do ontem e do hoje acerca do papel da enfermagem no processo e rotina da desinstitucionalização
}

\author{
Viviane Freitas Duarte ${ }^{1}$ \\ Gabriel Lavorato Neto ${ }^{2}$ \\ Larissa Rodrigues ${ }^{3}$ \\ Claudinei José Gomes Campos ${ }^{4}$
}

\begin{abstract}
Esta Revisão Integrativa objetiva explorar a produção científica nacional de enfermagem psiquiátrica sobre a reabilitação psicossocial no período de 1992 a 2014. A análise dos artigos levantados, resulta cinco categorias temáticas: enfermagem e a Reforma Psiquiátrica, ferramentas e estratégias que possibilitam a reabilitação psicossocial, o contexto familiar na reabilitação psicossocial, CAPS e outros espaços como facilitadores da reabilitação psicossocial e saúde mental na atenção básica. Nossas conclusões consideram a necessidade de um investimento maior na capacitação profissional do enfermeiro para compatibilizar com as demandas de cuidados aos doentes mentais apresentadas pela Reforma Psiquiátrica, que vem se consolidando paulatinamente com estratégias de inclusão que parecem adequadas, porém ainda insuficientes.
\end{abstract}

Descritores: Enfermagem Psiquiátrica; Desinstitucionalização; Reabilitação Psiquiátrica.

\footnotetext{
${ }^{1}$ Enfermeira, Hospital de Clínicas da Unicamp, Campinas, SP, Brasil.

${ }^{2}$ Mestrando, Faculdade de Enfermagem, Universidade Estadual de Campinas, Campinas, SP, Brasil. Professor, Faculdade Nazarena do Brasil, Campinas, SP, Brasil.

${ }^{3}$ Mestranda, Faculdade de Enfermagem, Universidade Estadual de Campinas, Campinas, SP, Brasil.

${ }^{4} \mathrm{PhD}$, Professor Doutor, Faculdade de Enfermagem, Universidade Estadual de Campinas, Campinas, SP, Brasil.
}

Correspondência:

Gabriel Lavorato Neto

Universidade Estadual de Campinas

Rua Tessália Vieira de Camargo, 126

Cidade Universitária Zeferino Vaz

CEP 13083-887, Campinas, São Paulo, Brasil

E-mail: lavorato.neto@gmail.com 


\title{
Academic sayings from the past and the present about the Nursing Role in the Process and Routine of Deinstitutionalization
}

This Integrative Review aims to explore the Brazilian scientific production of psychiatric nursing about psychosocial rehabilitation from 1992 to 2014 . The analysis of the surveyed articles results in five thematic categories: nursing and Psychiatric Reform, tools and strategies that provide psychosocial rehabilitation, family background in psychosocial rehabilitation, Psychosocial Care Centers and other spaces as facilitators of psychosocial rehabilitation and mental health in primary care. According to our conclusions greater investment in the nurses' professional training is necessary in order to fulfill the demands of care to the people with mental illness presented by the Psychiatric Reform, which has been slowly consolidating with inclusion strategies that seem appropriate, but still insufficient.

Descriptors: Psychiatric Nursing; Deinstitutionalization; Psychiatric Rehabilitation.

\section{Eses Académicos del pasado y del presente sobre el Papel de la Enfermería en el Proceso y Rutina de la Desinstitucionalización}

\begin{abstract}
Esta Revisión de integración objetiva explorar la producción científica nacional de enfermería psiquiátrica sobre la rehabilitación psicossocial en el período de 1992 a 2014. El análisis de los artículos levantados, resulta cinco categorías temáticas: enfermería y la Reforma Psiquiátrica, herramientas y estrategias que posibilitan la rehabilitación psicossocial, el contexto familiar en la rehabilitación psicossocial, CAPS y otros espacios como facilitadores de la rehabilitación psicossocial y salud mental en la atención básica. Nuestras conclusiones consideran la necesidad de una inversión mayor en la capacitación profesional del enfermero para compatibilizar con las demandas de atenciones a los enfermos mentales presentadas por la Reforma Psiquiátrica, que viene consolidándose de manera progresiva con estrategias de inclusión que parecen adecuadas, sin embargo aún insuficientes.
\end{abstract}

Descriptores: Enfermería Psiquiátrica; Desinstitucionalización; Rehabilitacíon Psiquiátrica.

\section{Introdução}

A concepção e o entendimento da doença mental variaram com o decorrer do tempo. O louco foi visto, até pouco tempo atrás, como um indivíduo privado de sua razão e, por isso, deveria ser cerceado de sua liberdade de escolha. Os asilos, ou hospícios, surgiram naquele contexto como uma solução para o problema do paciente psiquiátrico, a exclusão consequência da reclusão terapêutica (Internação) a qual era submetido, o que Ihe retirava a cidadania. O objetivo daquele modelo era devolvê-lo à sua razão e à liberdade por meio de um tratamento moral para que este indivíduo voltasse a ser um sujeito de direito. Deste modo, esta prática asilar tornou-se imperativa para todos os indivíduos sem posse da 
razão, pois eram considerados loucos, delirantes ou alucinados $^{(1-2)}$.

Hoje, essa prática de reclusão e exclusão desses indiíduos ainda existe, com ocorrências mais sutis, a despeito dos esforços de transformá-la, especialmente empreendidos pela chamada Reforma Psiquiátrica (RP): "Por não se admitir a exclusão, corre-se o risco de não se admitir a diferença. Esta não pode ser negada, é necessário reconhecê-la e conviver com ela sem ter que excluir, conforme a grande aspiração da Reforma Psiquiátrica”(3).

O Ministério da Saúde define a Reforma Psiquiátrica como "o processo político e social complexo, composto de atores, instituições e forças de diferentes origens, e que incide em territórios diversos, nos governos federal, estadual e municipal, nas universidades, no mercado dos serviços de saúde, nos conselhos profissionais, nas associações de pessoas com transtornos mentais e de seus familiares, nos movimentos sociais, e nos territórios do imaginário social e da opinião pública. Compreendida como um conjunto de transformações de práticas, saberes, valores culturais e sociais, é no cotidiano da vida das instituições, dos serviços e das relações interpessoais que o processo da RP avança, marcado por impasses, tensões, conflitos e desafios"(4).

Atualmente, na reflexão e na busca da utilização de recursos para tratamento nos CAPS's (Centros de Atenção Psicossocial), nas Residências Terapêuticas (RT's), e na proposta de retorno do sujeito psiquiatricamente acometido à comunidade, encontra-se a real proposta reformista que está em franco desenvolvimento.

O processo histórico nacional que culminou na alteração do modelo do atendimento psiquiátrico refletiu tendências mundiais, tendo como marcos: a crítica ao saber psiquiátrico e ao modelo hospitalocêntrico promovida pelo Movimento de Trabalhadores em Saúde Mental (MTSM) de 1978; a criação do sistema único de Saúde (SUS) em 1988 com princípios que serão integrados à RP e a atuação política em 1989 de Paulo Delgado propondo no Congresso Nacional a Lei de extinção e substituição do modelo vigente. A partir de 1992 surgem: os CAPS's, os NAPS's (Núcleos de Atenção Psicossocial) e os Hospitais-dia (HD); e, em 2001, a Lei 10.216 dispõe sobre os direitos das pessoas com transtornos mentais, proibindo no território nacional a construção de novos hospitais psiquiátricos e a contratação de leitos particulares pelo serviço público para o fim de internação psiquiátrica. Os tratamentos, a partir de então, deveriam atender aos princípios da
$\mathrm{RP}$ recuperando o paciente e reinserindo-o em seu meio social ${ }^{(4-5)}$.

Em 1999, temos a visão sobre a reabilitação descrita em eixos ${ }^{(6)}$ : pela capacidade para fixar residência dos ex-internos, trocar sentimentos e identidades; e produzir e trocar mercadorias e valores. Em relação à administração dos cuidados, dois processos da ressocialização( ${ }^{(7)}$ são adotados na nova visão psiquiátrica: um primeiro movimento de escuta e acolhimento dos desejos e das necessidades - que também estavam encarcerados-; e "posteriormente houve o estabelecimento de vínculo e a responsabilização de toda a rede de cuidados, no sentido de produzir novos e melhores modos de viver"(7). Ainda chama a atenção a possibilidade de promover a ressocialização e cumprimento das concepções da RP através da constituição teórica, política e ética da rede de atendimento(6-7).

No contexto de enfermagem anterior à RP, o trabalho se baseava em um serviço normativo, com o objetivo de manter a organização geral do estabelecimento psiquiátrico. Ao enfermeiro estava reservado um papel administrativo e burocrático, como organizar a escala de trabalho dos profissionais de nível médio sob sua supervisão, conferência de roupa (De paciente, de cama, de banho), de pertences (Do paciente, da enfermaria, do hospital), o afastamento sistemático do cuidado do paciente e inclusive o controle de outros profissionais, como visitas médicas, vigilância durante visitas familiares e durante as atividades de auxiliares e dos outros profissionais $^{(8)}$.

$\mathrm{Na}$ década de 80, havia um paradoxo no processo de formação de enfermagem entre o ensino e a ação( ${ }^{(8)}$. As bases teóricas da enfermagem norte-americana eram transmitidas no passado pelas escolas, faculdades e cursos de nível médio. Privilegiava-se a atitude terapêutica, sua técnicas de comunicação e seu relacionamento interpessoal, , noções de psicopatologia e a influência humanista do cuidado ao ser humano. Entretanto, a ação da enfermagem não focava o paciente e sua família, mas sim a manutenção do "ambiente terapêutico" para que as intervenções médico-centradas fossem realizadas plenamente e com maior amplitude. A ação da enfermagem estava sempre sob o controle da conduta médica, cabendo a ele solicitar a avaliação médica, administrar a medicação prescrita, realizar a contenção dos pacientes quando necessário e manter o paciente sob constante vigilância ${ }^{(8)}$.

O modelo psiquiátrico hospitalocêntrico, por ser guiado pelas ações médicas, ecoava o paradoxo da formação, privando a enfermagem de qualquer 
autonomia para sua prática. De um contexto rígido e sem alternativas, este padrão foi profundamente alterado, tanto pelas responsabilidades erigidas no processo reformador, como pelas novas tendências dos modelos de prática e cuidados adotados pela enfermagem ao redor do mundo.

No presente, existe a necessidade de ações interdisciplinares dentro dos serviços articulados na rede básica, compreendendo o trabalho interligado de assistente social, enfermeiro, médico, psicólogo e terapeuta ocupacional, entre outros, e que constitui uma questão inovadora no processo. Dentro da equipe, o enfermeiro vem exercendo não somente o papel de custódia dos pacientes, mas sim voltando suas ações em abordagens psicológicas e sociais que são pouco exploradas até o momento(9).

Considerando que o papel da enfermagem e a natureza de seu processo de trabalho, em momento disparador, sofrem alterações paradigmáticas que conferem a eles autonomia e fortalecimento de seus vínculos interdisciplinares no processo terapêutico do doente mental, ocorreu o interesse temático que é comum à linha de nosso grupo de pesquisa. Assim, resolvemos atualizar, estender e discutir o Trabalho de Conclusão de Curso de um dos membros de nosso grupo de pesquisa, e que nos serve de base para esta produção. Para tanto, identificamos nos bancos de dados acadêmicos as produções científicas nacionais de enfermagem psiquiátrica sobre a reabilitação psicossocial (Primeiro nome atribuído aos efeitos promovidos pela RP), catalogando delas as contribuições e os temas acerca dos avanços registrados. Novos moldes e nomes sobre estes efeitos foram agregados, até o momento, e registrados na produção científica. Este fato evidencia o estatuto processual de implementação da RP.

\section{Objetivo}

Explorar as produções científicas nacionais da enfermagem sobre o processo histórico a respeito da desinstitucionalização e da reabilitação psicossocial proveniente da RP brasileira e avaliar seu processo de desenvolvimento.

\section{Metodologia}

Este estudo tem por objetivo uma revisão integrativa de literatura, método de pesquisa que "tem a finalidade de reunir e sintetizar resultados de pesquisas sobre um delimitado tema ou questão, de maneira sistemática e ordenada, contribuindo para o aprofundamento do tema investigado"(10).
Exploramos os novos modelos de atenção psiquiátrica devido à significativa alteração neles prescritos a respeito do trabalho para o qual se convocou a enfermagem. A documentação científica é o registro evidente da implementação do modelo. Ela nos dá condições para efetuarmos uma avaliação entre o ideal preconizado pelos manuais que instalaram a RP, a desinstitucionalização e a reabilitação psicossocial, com o seu andamento e as reais condições de sua prática. Este tipo de comparação permite averiguar tanto o segmento histórico do processo quanto a aferição empírica do mesmo. Por fim, provê os dados que facilitam a inovação do conhecimento e adoção de medidas que objetivem aprimorar os serviços de saúde envolvidos no processo.

Para esta revisão foram utilizadas publicações de artigos brasileiros, entre janeiro de 1992 e setembro de 2014. Os documentos foram catalogados através de buscas sistemáticas na: 1) Biblioteca Virtual em Saúde (BVS); 2) nas bases de dados eletrônicas LILACS, Medline; 3) na Biblioteca Eletrônica Scielo; e nas bases de dados em áreas especializadas (BDEnf - Base de dados de enfermagem). Os seguintes descritores foram utilizados e cruzados: enfermagem, desinstitucionalização, reabilitação psicossocial. Os dois primeiros descritores (Desinstitucionalização e enfermagem) foram definidos a partir de uma busca nos Descritores em Ciências da Saúde (DeCS) da BVS. O terceiro (Reabilitação psicossocial), não está contido naqueles descritores. Contudo, como resultado da discussão de nosso material no Grupo de Pesquisa, prevaleceu a opinião sobre a importância de incluí-lo como palavra-chave na busca. Esclarecemos que, para a busca dos artigos produzidos na faixa de 1992 a 2004, utilizamos os descritores "desinstitucionalização" e "enfermagem". O terceiro descritor não gerou resultados quando inserido nas bases, com a percepção de que ele começou a ser paulatinamente utilizado a partir de 2005 , e então se tornou mais presente na produção acadêmica ligado ao tema.

Dos resultados obtidos nas bases de dados, selecionamos através da leitura dos resumos e seus descritores, os artigos que atendiam ao nosso tema. Para a amostragem estabelecemos os seguintes critérios: acesso ao texto integral em sua fonte; discussão relevante sobre o tema proposto; serem produzidos no período entre janeiro de 1992 e setembro de 2014; haver correlação com o cenário de enfermagem seja pelo vínculo autoral à área (Docente, aluno ou professor), ou pelo desdobramento do contexto sobre ela. Foram incluídos e integrados 
em nossos resultados 39 artigos, além dos que nos serviram de aporte para a introdução e para a discussão do conteúdo integrado.

Os artigos lidos foram avaliados minuciosamente. Do conjunto de dados, os pesquisadores selecionaram recortes temáticos que serviram de elementos para o agrupamento categórico a seguir apresentado, o qual objetiva responder as intrigas sobre o andamento do processo da RP em nosso país e, especialmente, como ele afeta a produção científica no contexto da enfermagem em saúde mental no Brasil .

\section{Resultados e Discussão}

\begin{tabular}{lll}
\hline Autor/Ano & Objetivos & Desenho \\
\hline
\end{tabular}

Sousa KKB

de, Filha $F$

Oliveira M

de, Silva

ATMC.

2001
Qualitativo

(Materialismo

Histórico e

Dialético).

Amostra $=4$
Descrever as concepções dos enfermeiros que atuam no Programa Saúde da Família - PSF sobre o processo de trabalho de enfermagem, as características desse processo, e, identificar os aspectos do processo saúde-doença que estes enfermeiros abordam com maior e menor freqüência, no cotidiano de sua prática profissional.
Existem saberes e práticas que orientam e auxiliam no trabalho dos sujeitos, que desenvolvem ações de enfermagem capazes de subsidiar uma aproximação com a superação das contradições reveladas, para adensar a construção de uma práxis, requerida na atualidade, que responde às necessidades de atenção à saúde mental, no sentido da inclusão social da pessoa com doença mental. O PSF é uma estratégia para a efetivação do SUS e como tal, um instrumento que pode ser empregado no sentido da municipalização das ações de saúde mental, aproximando essa área específica com o SUS e permitindo o avanço do movimento pela Reforma Psiquiátrica.

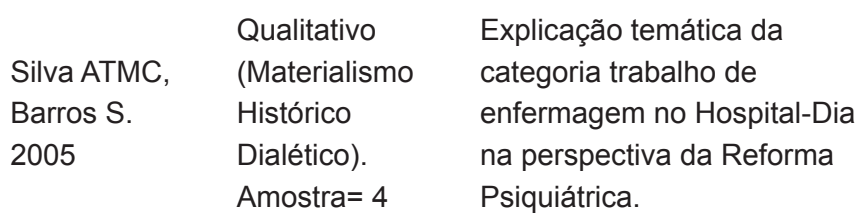

Terra MG, Ribas DL, Artigo de Sarturi F, Reflexão Erdmann AL 2006
Vislumbrar possibilidades de um novo paradigma onde o ser humano possa ser visto como não mais como uma doença. um cidadão em sofrimento e
A Reforma Psiquiátrica incorporou ao trabalho de enfermagem, além das competências da qualidade formal, técnica-especializada, a qualidade política frente ao tema: mudar o modelo de assistência psiquiátrica tradicional.
Jorge MSB, Abreu AGC de, Lopes $\mathrm{CHA}$ de $\mathrm{F}$, Morais APP, Guimarães JMX. 2008
Necessidade de revisão sobre a maneira de lidar com os seres em sofrimento psíquico, que exigem novas formas de assistir da enfermagem, através de um compromentimento constante dos trabalhadores de saúde mental. Um cuidado centrado do ser humano (Com seus direitos), e a importância da consolidação das práticas de enfermagem em serviços alternativos. 


\begin{tabular}{|c|c|c|c|}
\hline Autor/Ano & Objetivos & Desenho & Resultados \\
\hline
\end{tabular}

\section{Casanova}

EG,

Porto IS,

Figueiredo

NMA.

2006
Avaliar como as iniciativas desenvolvidas pela Direção do Serviço de Enfermagem contribuíram na aproximação ou distanciamento às bases conceituais do cuidado e aos princípios da Reforma Psiquiátrica com respeito ao olhar e agir da equipe de enfermagem.
Duas dimensões coexistentes: 1) instrumental que mostrou a proeminência do modelo asilar se sobrepondo às propostas de transformação; 2) expressiva, que mostrou que a principal demanda da clientela, e fenômenos fundamentais para a transição do modelo assistencial vigente para da reabilitação psicossocial, foi a valorização de suas singularidades e incorporação da diversidade e o acolhimento dos profissionais.

$\begin{array}{lll} & \text { Estudo } & \\ & \text { de Caso } & \text { Analisar as concepções dos } \\ \text { Qualitativo } & \text { trabalhadores de enfermagem } \\ \text { Kirschbaum } & \text { (Pesquisa } & \text { sobre: finalidade, objeto e } \\ \text { DIR. } & \text { documental, } & \text { instrumentos de trabalho } \\ 2009 & \text { observação } & \text { utilizados para desenvolver os } \\ & \text { participante e } & \text { cuidados de enfermagem aos } \\ & \text { entrevistas). } & \text { sujeitos psicóticos. }\end{array}$

Estudo

Qualitativo

observação

entrevistas).
Há diversidade no modo de conceber finalidades e características do objeto devido a coexistência de três distintos saberes que embasam a formação de cada concepção: a que se inspira na Atenção, Reabilitação Psicossocial e na Psicanálise; a que ressignifica princópios de vertentes da Reabilitação e resgata aspectos do tratamento moral; e a ideia de núcleo e campo profissional. É necessário invertir na produção do corpus conceitual para formação dos trabalhadores do CAPS.
Guimaräes

$\mathrm{J}$, Medeiros

SM.

Relato de

experiência.

2004
Relatar uma experiência de ensino da disciplina Enfermagem Psiquiátrica no período entre meados da década de 1980 até meados dad década de 1990.
Primeira experiência na mudança de currículo da disciplina de saúde mental, apontando a possibilidade de explorar a perspectiva da desinstitucionalização em psiquiatria, pensando na garantia do direito de cidadania aos pacientes e familiares que utilizam os serviços de saúde mental. Os autores ressaltam resistências sociais a esse tipo de raciocínio e observam a importância de discussões em sala de aula sobre as experiências de desinstitucionalização que começava a ser disseminada no país.
Silva DS, Azevedo Qualitativo DM. 2011
Investigar as percepções dos profissionais de enfermagens no SRT sobre a reforma Psiquiátrica e sua relação com sua formação.
Reforma Psiquiátrica: um movimentocomplexo com finalidade de modificar o trabalho na área de Psiquiatria; motiva o profissional à uma nova posição (Horizontal e humanizada) em relação ao doente.
Dutra VFD. Qualitativo. $2011 \quad$ Amostra $=12$
Descrever, na perspectiva de pacientes e familiares, o cuidado às pessoas em processo de desinstitucionalização.
O sucesso das altas se deve ao investimento dos profissionais (Com o destaque de sua competências técnicas e humanas), solidariedade familiar e comunitária, a viabilidade dos recursos materiais, a ao CAPS oferecendo apoio, referência e segurança. 


\begin{tabular}{|c|c|c|c|}
\hline Autor/Ano & Objetivos & Desenho & Resultados \\
\hline $\begin{array}{l}\text { Oliveira } \\
\text { FB de, } \\
\text { Fortunato } \\
\text { ML. } \\
1998\end{array}$ & $\begin{array}{l}\text { Artigo de } \\
\text { Reflexão }\end{array}$ & $\begin{array}{l}\text { Interpretar a institucionalização } \\
\text { do asilo, da psiquiatria, da } \\
\text { doença mental e o processo da } \\
\text { reforma psiquiátrica, buscando } \\
\text { contribuir para as reflexões } \\
\text { acerca da desinstitucionalização } \\
\text { e dos saberes e práticas de } \\
\text { enfermagem em saúde mental. }\end{array}$ & $\begin{array}{l}\text { O conhecimento da saúde mental durante o } \\
\text { movimento de RP deve ser aberto e complexo } \\
\text { de forma que estimule a busca, reflexão e } \\
\text { intuição, à partir desse ponto o enfermeiro } \\
\text { deve reaprender a aprender, para tanto há } \\
\text { que se propor projetos bem definidos, que } \\
\text { permitam experimentação e transformação } \\
\text { científica e prática iniciando com o raciocínio } \\
\text { crítico e a auto critica cotidiana em dinâmica } \\
\text { de mudança de paradigma. }\end{array}$ \\
\hline
\end{tabular}

Silva ATMC

da, Silva CC

da, Nóbrega

MML da,

Filha F,

Oliveira M

de, Sousa

KKB.

2004
Reflexão

Teórica com Discutir o trabalho de

revisão

bibliográfica.
Enfermagem na Perspectiva da

Reforma Psiquiátrica.
Necessidade de mudança do modelo de atenção à saúde no Brasil, na perspectiva da inclusão das questões da saúde mental nas estratégias do SUS, o que significa a efetivação da Reforma Psiquiátrica proposta no país, a partir do trabalho para produzir saúde mental no qual destacamos as mudanças necessárias no processo de trabalho de Enfermagem no Programa de Saúde da Família.

$\begin{array}{lll}\text { Campos } & \text { Qualitativo, } & \\ \text { N de L, } & \text { avaliador de } & \text { Descrever a utilização } \\ \text { Kantorskil } & \text { intervenção } & \text { da música numa Oficina } \\ \text { LP. } & \text { (Pesquisa- } & \text { Terapêutica de cuidado com o } \\ 2008 & \text { ação) grupal. } & \text { Corpo. } \\ & \text { Amostra=7 } & \end{array}$

Esta prática de enfermagem foi um instrumento facilitador do vínculo e do diálogo entre os participantes, contribuiu para elevar a auto-estima e estimular o autocuidado dos pacientes.
Pitiá AC de A, Furegato ARF.

2009

\section{Artigo de} Reflexão
Discutir o processo de reabilitação psicossoal e o Acompanhamento Terapêutico (AT) em saúde mental.
Considera à importância da consolidação de uma rede de atenção que possibilite perspectiva de vida aos portadores de sofrimento psíquico como um desafio a ser enfrentado que considere prioritariamente o sujeito implicado nessa situação e seu contexto de imersão social.
Cassandri JL, Silva A e, Luisa A. 2009
Compreender a ação dos trabalhadores na Copa da Inclusão (Processo de trabalho),como essa ação considera a vida real do paciente do serviço de saúde mental.
Ribeiro LA

Sala ALB,

Oliveira

AGB.

2008
Qualitativo

(Observação

Participante)
Analisar as oficinas terapêuticas dos CAPS's e sua congruência com o modo de atenção psicossocial.
A ação promove transformações na vida dos pacientes dos serviços e da sociedade coerentes com os pressupostos da RP.
As duas categorias emergentes comparam a contradição dos centros que estimulavam a participação dos pacientes como uma estratégia de intervenção, e outra que havia descaracterização das atividades, tidas como passa tempo. As duas categorias: 1) "Oficinas na lógica da atenção psicossocial", a expressão de sentimentos dos pacientes era estimilada como forma de cuidar e intervir no processo de exclusão; 2) "Face nova para antigas práticas”, em alguns serviços as oficinas eram realizadas como passatempo. 


\begin{tabular}{lll}
\hline Autor/Ano & Objetivos & Desenho \\
\hline
\end{tabular}

Lima ICS,

Silva LD da

$C$ e, Moura MEBMEB,

Brito JNP de

O, Mesquita

Qualitativo.

Amostra $=9$

GV, Tapety

$\mathrm{FI}$.

2012
Analisar a vivência do familiar cuidador da pessoa com esquizofrenia, frente à reforma psiquiátrica.
As práticas terapêuticas do CAPS promovem melhora da qualidade de vida do doente e do cuidador, o que modifica a concepção da família e sociedade sobre a reclusão do doente mental; faz do CAPS alternativa eficaz ao modelo manicominal.
Reinaldo AM

dos S, Luis

$\mathrm{V}$, Antonia

Conceitual.

M.

2006
Oferecer aos enfermeiros psiquiátricos da assistência e ensino um repertório de possibilidades de trabalho com o doente mental.
Baseado nos modelos de países que fizeram com que a prática de gerenciamento de casos voltasse a ser uma alternativa viável, Oferece aos enfermeiros psiquiátricos da assistência e do ensino um repertório de possibilidades de trabalho com o doente mental que ampliem sua autonomia, dado que isso também integra as ações do cuidar.

$\begin{array}{lll} & & \begin{array}{l}\text { Apresentar conceitos que } \\ \text { embasam a prática do }\end{array} \\ \text { Soares MH. } \quad \text { Revisão } & \text { Bibliográfica. } \quad \begin{array}{l}\text { gerenciamento de casos em } \\ \text { saúde mental, promover o } \\ \text { conhecimento deste modelo de } \\ \text { administração da assistência } \\ \text { em saúde mental. }\end{array}\end{array}$

Características do gerenciamento de casos e do gerenciador de casos, a prática do gerenciamento de casos e o enfermeiro e a avaliação de resultados do gerenciamento de casos. É importante que esta estratégia seja discutida na enfermagem psiquiátrica, para contribuir com a desinstitucionalização e a reabilitação psicossocial.

$\begin{array}{lll}\begin{array}{l}\text { Argiles CTL, } \\ \text { Kantorski } \\ \text { LP, Willrich }\end{array} & \text { Qualitativo, } & \begin{array}{l}\text { Conhecer a rede de } \\ \text { sociabilidade dos pacientes do } \\ \text { JQ, }\end{array} \\ \text { Antonacci } & \begin{array}{l}\text { estudo de } \\ \text { Caso. }\end{array} & \begin{array}{l}\text { serviço residencial terapêutico, } \\ \text { avaliando experiências } \\ \text { MH, }\end{array} \\ \text { inovadoras em composição de } \\ \text { VCC. }\end{array}$

Como um serviço de experiência singular e inovadora, constrói saídas para o desafio de aproximar pessoas com extensos períodos de internação psiquiátricas a seus familiares, à comunidade e à vida da cidade, rompendo com a segregação. As aprendizagens de moradores e trabalhadores demonstram potencialidades para concretizar a reinserção cidadã dos portadores de sofrimento mental à sociedade.

$\begin{array}{ll}\text { Colvero L de } & \text { Qualitativo, } \\ \text { A, Ide CAC, } & \text { Representa- } \\ \text { Rolim MA. } & \text { ções Sociais } \\ 2004 & \text { (Moscovici). }\end{array}$

Identificar as representações sociais construídas por familiares acerca do fenômeno saúde doença mental.
Os familiares explicitam sua não aceitação daquele que se mostra diferente, como núcleo de suas representações sociais. Apontamos para a importância dos profissionais de saúde mental considerarem, em suas intervenções, o saber produzido pelos familiares.

\begin{tabular}{|c|c|c|}
\hline $\begin{array}{l}\text { Brischiliari } \\
\text { A, Waidman }\end{array}$ & $\begin{array}{l}\text { Qualitativo } \\
\text { (História }\end{array}$ & $\begin{array}{l}\text { Revelar na ótica familiar a } \\
\text { participação acometido de }\end{array}$ \\
\hline MAP. & Oral). $\mathrm{N}=14$ & torno mental na vida em \\
\hline 012 & Amostra $=14$ & níla \\
\hline
\end{tabular}

Há restrições e limitações na participação das decisões familiares e tarefas cotidianas. Os sentimentos familiares são permeados por sofrimento atrelado a pena e dó. Aponta o importante papel de enfermagem na orientação e apoio familiar. 


\begin{tabular}{|c|c|c|c|}
\hline Autor/Ano & Objetivos & Desenho & Resultados \\
\hline
\end{tabular}

$\begin{array}{lll}\text { Hirdes A, } & \text { Qualitativo } & \begin{array}{l}\text { Abordar o comprometimento } \\ \text { e envolvimento da família }\end{array} \\ \text { Kantorski } & \text { (Materialismo } & \begin{array}{l}\text { no processo de reabilitação } \\ \text { LP. }\end{array} \\ 2005 & \text { dialético ). } & \begin{array}{l}\text { psicossocial na ótica de } \\ \text { profissionais do CAPS. }\end{array}\end{array}$

A inclusão familiar no setting terapêutico é uma exigência institucional que conduz ao estabelecimento de estratégias de intervenção mais abrangentes e consistentes, proporciona integração dinâmica através do manejo conjunto, diminui o abandono e subsidia projetos terapêuticos. O cuidado engloba mais do que os aspectos psiquiátricos, vai ao contexto de vida dos pacientes.

$\begin{array}{ll}\text { Waidman } & \text { Pesquisa } \\ \text { MAP, Elsen } & \text { Bibliográfica } \\ \text { I. } & \text { Amostra }=41 \\ 2005 & \end{array}$

Identificar as referências e categorias emergentes sobre o cuidado multi e interdisciplinar em saúde mental.
As três categorias (Crítica ao cuidado oferecido por alguns profissionais; a necessidade de preparo do profissional para cuidar de famílias de portadores de transtorno mental e; a importância do profissional enquanto agente da desinstitucionalização e resinserção social do portador de transtorno mental), mostram que o trabalho interdisciplinar em saúde mental é um dos pressupostos para que a desinstitucionalização seja efetiva. Ressalva que, conforme pode ser observado neste estudo, os profissionais apresentam dificuldades em desenvolver essa forma de trabalho.

$\begin{array}{ll}\text { Oliveira } & \begin{array}{l}\text { Qualitativo } \\ \text { AMN de, }\end{array} \\ \text { Lunardi, da } & \text { nológico de } \\ \text { Silva MRS. } & \text { Heidegger) } \\ 2005 & \end{array}$

Waidman

MAP, Elsen Artigo de

I, Marcon Reflexão

SS.

2009

$\begin{array}{ll}\text { Waidman } & \\ \text { MAP, Elsen } & \text { Artigo de } \\ \text { Marcon } & \text { Reflexão } \\ \text { SS. } & \\ 0009 & \end{array}$

Desvelar e compreender os significados de cuidar e ser cuidado para o ser portador de doença mental e sua família de maneira a provocar reflexão do trabalho de enfermagem.
Foi possível compreender a necessidade da família de ser cuidada frente à manifestação da doença mental, principalmente, durante seu início. As famílias e o seu familiar doente manifestaram angústia e tristeza diante da internação no hospital psiquiátrico, em função da maneira como é prestado o cuidado nesta instituição, considerando que ela não promove sua reabilitação psicossocial.
Apresentar a teoria de Joyce Travelbee e analisar suas limitações e potencialidades, com o propósito de construir uma metodologia de cuidado à família de pessoas com transtornos mentais frente a desinstitucionalização e a sua reinserção na família e comunidade.
Aspectos positivos da teoria têm sido relevantes no auxilio de enfermeiros na abordagem de algumas situações, particularmente pelo apoio das concepções de unicidade do ser humano, relacionamento interpessoal com comprometimento emocional, comunicação autêntica e verdadeira e encontro de significados na doença e nas dificuldades surgidas no decorrer da vida, os quais mantêm relações entre si. 


\begin{tabular}{|c|c|c|c|}
\hline Autor/Ano & Objetivos & Desenho & Resultados \\
\hline $\begin{array}{l}\text { Cardoso L, } \\
\text { Galera SAF. } \\
2011\end{array}$ & $\begin{array}{l}\text { Quantitativo. } \\
\text { Análise } \\
\text { através de } \\
\text { tendência } \\
\text { central no } \\
\text { programa } \\
\text { estatístico } \\
\text { SPSS, versão } \\
10.0 \\
\text { Amostra= } 48\end{array}$ & $\begin{array}{l}\text { Identificar as características } \\
\text { sócio-demográficas dos } \\
\text { cuidadores de pessoas que } \\
\text { tiveram alta hospitalar de } \\
\text { internação psiquiátrica. }\end{array}$ & $\begin{array}{l}21 \text { pacientes possuíam cuidadores que eram } \\
\text { familiares, sendo que } 38 \% \text { eram as mães dos } \\
\text { doentes. Sobre os cuidadores: Idade média } \\
46,6 \text {; casados ou amasiados representavam } \\
61,9 \% \text {; apenas um cuidador não tinha filhos; } \\
\text { principal fonte de renda para } 28,6 \% \text { foi } \\
\text { trabalho enventual. Conhecer este perfil } \\
\text { permite fomentar a determinação do melhor } \\
\text { tratamento e suporte profissional ao cuidado } \\
\text { desta clientela. }\end{array}$ \\
\hline
\end{tabular}

\begin{tabular}{|c|c|c|c|}
\hline $\begin{array}{l}\text { Gomes MS, } \\
\text { Mello R. } \\
2012\end{array}$ & $\begin{array}{l}\text { Quantitativo } \\
\text { (Aplicação } \\
\text { de escala de } \\
\text { sobrecarga, } \\
\text { analisados } \\
\text { pela escala } \\
\text { Likert). } \\
\text { Amostra= } 10\end{array}$ & $\begin{array}{l}\text { Analisar o grau de sobrecarga } \\
\text { do principal cuidador que } \\
\text { convive com o portador de } \\
\text { esquizofrenia, em um hospital } \\
\text { de emergência psiquiátrica do } \\
\text { Estado do Rio de Janeiro. }\end{array}$ & $\begin{array}{l}\text { Foram encontradas sobrecargas elevadas } \\
\text { na rotina diária do familiar e intenso abalo da } \\
\text { sua saúde mental, sendo fundamental que a } \\
\text { enfermagem inclua as famílias no tratamento, } \\
\text { diminuindo as sobrecargas. }\end{array}$ \\
\hline
\end{tabular}

Ribeiro JP

Coimbra

VCC,

Borges AM.

Qualitativo.

2012
Compreender a diversidade de experiências dos famíliares do acomentido.
O familiar solicita acolhimento, escuta e ajuda para administrar a convivência com a pessoa em sofrimento mental. Para o familiar participar do cuidado ele precisa ganhar confiança, e o GF permite a construção do vínculo, otimiza a troca de aprendizagens e saberes, o que implica na corresponsabilização e satisfação do familiar com o cuidado.

$\begin{array}{lll}\text { Sadigursky } & \text { Artigo de } & \text { Desenvolve algumas } \\ \text { D, Tavares } & \text { Reflexão } & \text { considerações sobre o processo } \\ \text { JL. } & & \text { de desinstitucionalização. } \\ 2003 & & \end{array}$

Considera as dificuldades em se reverter a concepção e o estigma da loucura na sociedade, conformada ao longo da história, assim como, a consolidação de uma infraestrutura necessária a esse processo, a qual mantém relação direta com todos os sujeitos sociais e determinações políticas.

$\begin{array}{ll}\text { Matos BG } & \text { Qualitativo } \\ \text { de, Moreira } & \text { (Análise de } \\ \text { LH de O. } & \text { conteúdo } \\ 2013 & \text { temática). } \\ & \text { Amostra }=7\end{array}$

Descrever o processo de reinserção social dos moradores considerando o modelo de SR.
O Estudo aproximou-se da vivência dos sujeitos fora do manicômio e entendeu que o projeto terapêutico da RT aproxima-se dos paradigmas da Reabilitação Psicosossial. Percebeu-se a reconstrução social dos sujeitos como as práticas de integração destes com a comunidade e com seus companheiros de RT.

$\begin{array}{ll}\text { Loyola } & \\ \text { CMD, Pôrto } & \text { Quanti- } \\ \text { K da F, } & \text { qualitativa. } \\ \text { Rocha K } & \text { Amostra= 0 } \\ \text { da S } & \\ 2009 & \end{array}$

Características do gerenciamento de casos e do gerenciador de casos, a prática do gerenciamento de casos e o enfermeiro e a avaliação de resultados do gerenciamento de casos. É importante que esta estratégia seja discutida na enfermagem psiquiátrica, para contribuir com a desinstitucionalização e a reabilitação psicossocial. 


\begin{tabular}{|c|c|c|c|}
\hline Autor/Ano & Objetivos & Desenho & Resultados \\
\hline $\begin{array}{l}\text { Kantorski } \\
\text { LP, Souza J } \\
\text { de, Willrich } \\
\text { JQ, Mielke } \\
\text { FB. } \\
2006\end{array}$ & $\begin{array}{l}\text { Qualitativo, } \\
\text { (Análise } \\
\text { documental e } \\
\text { observação } \\
\text { participante). }\end{array}$ & $\begin{array}{l}\text { Descrever as práticas de } \\
\text { cuidado em saúde mental, } \\
\text { estruturadas em Centro de } \\
\text { Atenção Psicossocial (CAPS), } \\
\text { a partir dos pressupostos } \\
\text { teórico-práticos da reabilitação } \\
\text { psicossocial. }\end{array}$ & $\begin{array}{l}\text { As categorias temáticas: 1) Diretrizes da } \\
\text { organização institucional do Serviço; 2) A } \\
\text { equipe; 3) O cuidado em saúde mental no } \\
\text { cotidiano do serviço; 4) Os registros; levaram } \\
\text { à conclusão da necessidade do conhecimento } \\
\text { das práticas cotidianas do serviço objetivando } \\
\text { problematizá-las para que se possa de fato } \\
\text { promover a superação das práticas ailares. }\end{array}$ \\
\hline
\end{tabular}

Willrich JQ, Kantorski

LP,

Chiavagatti

FG, Cortes

JM, Pinheiro

GW.

2011
Dobjetiva conhecer os sentidos

Qualitativo

(Construciopresentes nas práticas discursivas dos profissionais acerca da atenção à crise nos Centros de Atenção Psicossocial (CAPS).
A compreensão dos sentidos de periculosidade e cidadania: a influência na construção de práticas de atenção à crise.

\section{Revisão}

Villela S de

C, Scatena

MCM.

2004

\section{bibliográfica}

em periódicos

nacionais no

período de

1999 a 2001
Analisar o processo de assistência de enfermagem ao doente mental em serviços externos ao hospital
O trabalho do enfermeiro deve estar focado na atenção primária para promover a saúde mental e desvelar junto ao paciente e familiares o sentido da enfermidade mental. Assim deve ter a prática de enfermagem baseada em percepção e observação, fazendo interpretações válidas no processo de enfermagem, enfatizando o relacionamento terapêutico, considerando como eixo da profissão o processo dinâmico e passível de mudanças
Lemos SS Lemos M, Souza M da GG. Análise de conteúdo) 2007
Identificar o preparo dos profissionais enfermeiros da UBSF (Unidade Básica da Saúde da Família) diante da doença e do doente mental, e qual a sua atuação para com este e sua família.
Os resultados revelaram a necessidade de qualificação e treinamento para trabalhar com Saúde Mental na rede básica, medidas de referência e contra-referência pouco utilizadas dificultando a continuidade da assistência prestada ao doente mental, ausência de Programas Psicoeducacionais para portadores de transtornos mentais e/ou familiares, e nos mostrou a importância de uma equipe qualificada e multiprofissional.
Brêda MZ,

Rosa W de

AG, Pereira

$\mathrm{MAO}$,

Scatena

MCM.

2005
Refletir sobre as Estratégias de Saúde da Família e de Reabilitação Psicossocial, no momento em que a atenção psiquiátrica e a atenção básica se colocam em estreita vinculação.
Identificando interfaces e desafios a serem superados para a transformação desses contextos sociais em espaços de trocas afetivas e materiais, de saberes e práticas mais criativas e flexíveis.

$\begin{array}{lll}\text { Mororó } & \begin{array}{l}\text { Qualitativo } \\ \text { (Análise da }\end{array} & \begin{array}{l}\text { Analisar e descrever as } \\ \text { potencialidades e dificuldades }\end{array} \\ \text { Colvero L de } & \text { cartografia } & \text { da equipe na construção dos } \\ \text { A, Machado } & \text { e de grupo } & \text { projetos } \\ \text { AL. } & \text { focal). } & \text { terapêuticos. } \\ 2011 & & \end{array}$

Identificou uma cisão entre as equipes noturna e a diurna, e a falta de espaços sistemáticos de conversa para elaboração e discussão dos projetos terapêuticos. 


\begin{tabular}{|c|c|c|c|}
\hline Autor/Ano & Objetivos & Desenho & Resultados \\
\hline $\begin{array}{l}\text { Mielke FB, } \\
\text { Olschowsky } \\
\text { A, Pinho LB } \\
\text { de, Wetzel } \\
\text { C, Kantorski } \\
\text { LP. } \\
2012\end{array}$ & $\begin{array}{l}\text { Qualitativo } \\
\text { (Avaliação } \\
\text { de Quarta } \\
\text { Geração, e } \\
\text { aplicação } \\
\text { adaptada } \\
\text { do Círculo } \\
\text { Hermenêuti- } \\
\text { co-Dialético). }\end{array}$ & $\begin{array}{l}\text { Avaliar a relação de atores } \\
\text { sociais com a loucura a partir } \\
\text { das experiências produzidas } \\
\text { em um Centro de Atenção } \\
\text { Psicossocial no contexto } \\
\text { brasileiro. }\end{array}$ & $\begin{array}{l}\text { Os depoimentos perseguem a } \\
\text { desinstitucionalização como paradigma da } \\
\text { atenção em saúde mental, evidenciando } \\
\text { a necessidade de combater os vícios } \\
\text { carregados de condutas cristalizadas e } \\
\text { excludentes, típicas do modelo manicomial. } \\
\text { No entanto, ainda é possível visualizar na } \\
\text { prática uma mescla de modelos, responsáveis } \\
\text { por práticas ampliadas e inovadoras, além de } \\
\text { outras cristalizadas e excludentes. }\end{array}$ \\
\hline $\begin{array}{l}\text { Nasi C, } \\
\text { Schneider } \\
\text { JF. } \\
2011\end{array}$ & $\begin{array}{l}\text { Qualitativo } \\
\text { (Sociologia } \\
\text { fenomenoló- } \\
\text { gica). } \\
\text { Amostra= } 13\end{array}$ & $\begin{array}{l}\text { Compreender o cotidiano de } \\
\text { pacienes de um (CAPS). }\end{array}$ & $\begin{array}{l}\text { Os pacientes consideram o CAPS como } \\
\text { uma dimensão do seu cotidiano; foram } \\
\text { compreendidas as concepções que os } \\
\text { pacientes têm acerca do seu cotidiano e } \\
\text { como estão (re)adquirindo o convívio social. } \\
\text { Considera que o os CAPS estão promovendo, } \\
\text { além do entendimento, a rabilitação } \\
\text { psicossocial dos seus pacientes. }\end{array}$ \\
\hline
\end{tabular}

Figura 1 -Artigos Integrados nos Resultados.

Após a leitura e análise dos artigos, estes foram agrupados de acordo com as seguintes categorias temáticas: 1) A Enfermagem e a Reforma Psiquiátrica (11 artigos); 2) Ferramentas e Estratégias que possibilitam a reabilitação psicossocial (8 artigos); 3) O Contexto familiar na reabilitação psicossocial (9 artigos); 4) CAPS e outros espaços como facilitadores da reabilitação psicossocial (5 artigos); e 5) Saúde Mental na Atenção Básica (6 artigos).

Uma análise comparativa do volume das publicações pode ser relacionada da seguinte forma: 13 artigos produzidos na década de 2010-14; 25 artigos produzidos entre os anos 2000-09; um artigo produzido no ano 1998 (Primeira referência indexada na BVS de um artigo sobre as diretrizes da RP e seu impacto nos saberes e práticas de enfermagem em Saúde Mental); Quanto ao desenho dos estudos: 25 são qualitativos; 2 quantitativos; 1 é quanti-qualitativo; 7 são artigos de reflexão ou relatos de experiência; 3 são artigos de Revisão; um artigo é conceitual.

O volume ascendente da produção, o espectro qualitativo predominante nos desenhos dos estudos, com a ampla avaliação dos fenômenos em campo, e a natureza das discussões com a produção de reflexões e revisões, sugerem o movimento no interesse de pesquisa: como os conceitos da RP, da humanização e da desinstitucionalização se implementaram, e como uma preconização filosófica e política afetou saberes e ações nos âmbitos dos cenários assistências à Saúde Mental e suas consequências na sociedade brasileira. É neste sentido que apontamos e discutimos a seguir os resultados das análises temáticas nas quais enquadramos nossas referências.

\section{A Enfermagem e a Reforma Psiquiátrica}

O trabalho da enfermagem enfrenta um desafio no cenário da RP, que consiste em abandonar a antiga mentalidade do modelo asilar de custódia, adotando a nova política de saúde mental tendo como objetivo a inclusão social. O enfermeiro, além de seu papel junto ao paciente e todo seu contexto, deve preocupar-se com a criação de um raciocínio reformista na sua equipe (Auxiliares e técnicos de enfermagem e agentes comunitários de saúde) sob sua supervisão.

Em 2004, em um estudo qualitativo com enfermeiros da atenção básica, especificamente atuantes no programa de saúde da família, foi relatado que o entendimento desses profissionais sobre o atendimento do paciente com transtorno mental era a distribuição e o controle das medicações utilizadas por eles, psicotrópicos na grande maioria, sem grandes reflexões acerca de outras atividades assistenciais ${ }^{(11)}$.

É importante salientar a necessidade de novas atividades na prática da enfermagem que envolva "o acolhimento, a humanização das relações entre os sujeitos implicados com a assistência em saúde mental e o envolvimento dos familiares com o serviço"(12).

A subjetividade dos trabalhadores de enfermagem remete à exposição diária de uma rotina difícil com 
diversos estressores. Por isso, é necessário que a enfermagem seja auxiliada a criar espaços de reflexão sobre a qualidade dos serviços para que estes possam avançar, envolvendo o grupo de profissionais, pacientes e família, objetiando a reconstrução da vida e o redirecionando do foco de atenção da doença para o indivíduo em sofrimento ${ }^{(13)}$. Uma das condições para minimizar esses estressores é a humanização do trabalho, que é vista como um dos instrumentos que pode ofertar uma melhor condição de cuidado ao cuidador em saúde mental(14), da mesma maneira que é o foco da ação reformista, visto que a Política Nacional de Humanização (PNH) entende humanização como inclusão(15).

Nesses espaços para repensar a assistência, que podem ser grupos de supervisão ou reflexão, se faz possível à equipe de enfermagem exteriorizar as dimensões relativas ao cuidado, levando ao amadurecimento dos profissionais, possibilitando também entender a influência do ambiente nos cuidados da enfermagem psiquiátrica ${ }^{(16)}$.

As características do trabalho de enfermagem junto a psicóticos, desenvolvido em um CAPS e serviços de RT, "são marcadas pela construção de conexões pouco claras entre a finalidade, o objeto e os instrumentos de trabalho devido à multiplicidade de saberes e concepções de sujeito e de clínica que sustentam as distintas tecnologias de processo de trabalho, convivendo num mesmo espaço institucional"(17). Com isso, perceber-se a necessidade de organizar as formas de trabalho nesses espaços para que o cuidado aos indivíduos seja mais específico, e o plano terapêutico tenha mais êxito.

Agora, com relação ao ensino de enfermagem na área de saúde mental, foi observado que as disciplinas curriculares, apesar de enfatizarem a RP, continuam realizando seus estágios curriculares na área da saúde metal em hospitais psiquiátricos, contribuindo para a manutenção do modelo manicomial(12). Existem relatos de algumas exceções em que o aluno passou a enxergar o doente como um sujeito de direitos, que deve ter acesso a sua autonomia e cidadania ( Caso isso tenha sido negado ). Desta maneira, profissionais em formação voltarão suas práticas à transformação da assistência psiquiátrica na área da enfermagem, modificando assim a forma como a pessoa com doença mental é atendida e encaminhada ${ }^{(16)}$. O primeiro estudo publicado com o olhar para experiência dessa mudança de currículo da disciplina de saúde mental vem do nordeste, apontando a possibilidade de explorar a perspectiva da desinstitucionalização em psiquiatria, pensando na garantia do direito de cidadania para os pacientes e familiares que utilizam os serviços de saúde mental. O currículo vem sendo modificado desde 1996; em 2001 os autores ressaltam a existência de resistências sociais a esse tipo de raciocínio, e observam a importância de discussões em sala de aula sobre as experiências de desinstitucionalização que começava a ser disseminada no país, como até hoje é tema para reflexão em ambientes de estudo e prática de enfermagem. As dificuldades encontradas para implementação da RP não devem servir de álibi para a omissão, e sim de estímulo para procura de novos caminhos. O ensino voltado para as condições de vida e trabalho na coletividade e na particularidade de cada indivíduo foi significativo para a instituição, permeando discussões filosófico-pedagógicas e solidificando essa ideia nos estudantes ${ }^{(18)}$.

As transformações de uma enfermaria num espaço terapêutico também aparecem como influenciadoras na prática da enfermagem. Criar esse ambiente é função de todas as pessoas que lidam e interagem com o paciente. A abertura das portas cria uma nova configuração desse espaço que antes era usado para segregar esses pacientes. Assim, a enfermagem deve se adaptar para buscar consonância com a $\mathrm{RP}$, atendendo as necessidades e direitos desses indivíduos ${ }^{(16)}$.

O enfermeiro deve expandir seus papéis profissionais em saúde mental, acurar suas noções de acolhimento, escuta terapêutica e trabalho interdisciplinar. As novas metodologias adotadas nos serviços e no ensino podem favorecer o estabelecimento de novas práticas e saberes nesse contexto $^{(19)}$.

O profissional deve agir como um facilitador para que o indivíduo possa reorganizar sua vida pessoal e as relações sociais que tinha anteriormente à doença, pois é o paceinete quem deve buscar novas formas de autonomia e assim voltar a ser independente dos cuidados dos profissionais da saúde ${ }^{(19)}$.

Em meio ao processo de mudanças, os profissionais de saúde mental são desafiados a uma adequação para um novo campo de conhecimento, e a (re)construir novas práticas de saúde, elegendose a saúde mental e os novos serviços de tratamento (Substitutivos) como espaços práticos de cuidados voltados ao processo saúde-doença mental do paciente e família(19). A interpretação das diretrizes da Política Nacional de Saúde Mental pode sofrer múltiplas influências, a do modelo manicomial, o que pode restringir a ação dos espaços substitutivos, como uma que se alia a Política Nacional de Saúde Mental. 
O portador de transtorno mental necessita da construção de rede, onde estão inseridos os profissionais de saúde, pacientes, familiares, gestores e comunidade, atores e intérpretes das diretrizes, enquadrados em diferentes cenários, que influenciam na efetividade das medidas reformistas existentes $^{(19)}$.

O processo de alta foi um movimento de diferenciação entre a identidade do interno e da instituição. Esse movimento ocorreu no âmbito dos pensamentos, dos sentimentos e da atitude, fazendo com que, todos os caminhos para este cuidado em saúde mental passem pelo relacionamento terapêutico: a relação entre duas pessoas orientada por estratégias profissionais de ajuda ao outro. Assim, o preparo do profissional enfermeiro, como de toda equipe multiprofissional deve considerar o relacionamento ${ }^{(20)}$.

O conhecimento da saúde mental durante o movimento de RP deve ser aberto e complexo, de forma que estimule a busca, a reflexão e a intuição. A partir desse ponto, o enfermeiro deve reaprender a aprender, para tanto há que se propor projetos bem definidos, que permitam experimentação e transformação científica, e prática iniciando com o raciocínio crítico, autocrítica cotidiana sobre a mudança dinâmica de paradigma(21).

\section{Ferramentas e Estratégias que possibilitam a reabilitação psicossocial}

Passar a praticar o cuidado e promoção à saúde mental na atenção primária requer redirecionamento de foco e de instrumentalização à equipe de saúde. O enfermeiro deve construir e utilizar esses recursos para reinserção do paciente com transtornos mentais em comunidade, assim, respeitando o princípio de integralidade pressuposto no Sistema Único de Saúde ${ }^{(22)}$.

Com o desenvolvimento da RP surgiram diversos tipos de recursos que tinham por objetivo a desinstitucionalização e, consequentemente, a reabilitação psicossocial com foco na autonomia do cidadão. Para recuperar essa autonomia, hoje se fala em projeto terapêutico individual (PTI), instrumento caracterizado pelo estabelecimento de metas e planejamento de atividades dentro dos espaços de saúde mental, para o alcance desses objetivos pelo indivíduo sob cuidados ${ }^{(23)}$.

A princípio descrevemos o recurso do Acompanhamento terapêutico (AT), que consiste na prática de um acompanhante propiciar presencialmente ao indivíduo acometido pela doença mental saídas pela cidade em atividades cotidianas, com o objetivo de desenvolver no mesmo habilidades de reinserção social. Um processo que acontecerá sempre de acordo com a execução do projeto terapêutico individual ( $\mathrm{PTI})$, objetivando o processo de reabilitação psicossocial do sujeito atendido(23). Nessa prática, o acompanhante terapêutico não tem uma profissão em particular, mas tem uma formação específica para a prática, com característica interdisciplinar ${ }^{(24)}$.

Outro recurso empregado como instrumento da reforma para integração comunitária, de amplo espectro, entre acometido de transtorno mental e sociedade foi a Copa da Inclusão, valorizando o esporte, que consiste num campeonato de futsal entre oficinas e outros espaços, para a participação de todos. Os organizadores do evento são das mais diversas áreas: psiquiatras, enfermeiros, psicólogos e educadores físicos. Esse evento, que é uma parceria entre entidades universitárias e equipamentos substitutivos, envolve pacientes, trabalhadores, familiares e pessoas da comunidade. Atendendo a um dos requisitos fundamentais da reintegração, o projeto promove ao paciente, a sua família e a sociedade que o circunda, uma articulação de convívio além de provocar uma "diminuição do estigma da loucura", evidenciada pela aproximação da comunidade durante as atividades esportivas ${ }^{(25)}$

As oficinas terapêuticas são instrumentos ricos que possibilitam, durante o trabalho e a realização de práticas artísticas, a socialização e a interação social de pacientes e profissionais; consequentemente a reinserção social. Nelas, o sujeito lida com seus medos, inseguranças, e também troca experiências. Os profissionais ajudam o sujeito em crise a se integrar às atividades trazendo-o de volta para o convívio social(26). Monitoradas por profissionais de diversas áreas - enfermagem, psicologia, terapia ocupacional, educação física, etc.- é considerada benéfica, pois "contribui para a produção de novas maneiras de intervir no sofrimento mental"(26). A liderança da oficina é fundamental para a reflexão que a mantenha na função terapêutica, o que demanda a capacitação desse profissional ${ }^{(26)}$.

A música também é utilizada para facilitar o vínculo, o diálogo, elevar a autoestima e provocar o autocuidado entre os participantes de uma oficina terapêutica de cuidado com o corpo num CAPS. Ela é o meio de estimular o olhar e o querer cuidar de si, pois tem o poder de modificar o estado de espírito; pode adquirir significados individuais quando articulada com as experiências de vida das pessoas. A utilização desse meio resultou em uma motivação 
maior dos pacientes a participarem dessas oficinas e a comparecerem mais limpos e arrumados, mostrando dessa forma que as suas identidades vinham sendo reintegradas ${ }^{(23)}$.

Neste momento, o gerenciamento de casos foi documentado como uma estratégia de trabalho para profissionais de enfermagem psiquiátrica, considerando o aspecto psicossocial e a reinserção dos pacientes na sociedade: "a ideia básica é que ele deveria combinar e coordenar diferentes serviços para pacientes psiquiátricos vivendo na comunidade, promovendo um acompanhamento dessas pessoas e viabilizando seu melhor funcionamento 'prático' na comunidade"(27). É uma prática de enfermagem que ainda exige uma conceituação mais clara e precisa, mas foi demonstrado que os enfermeiros psiquiátricos comunitários que utilizam o gerenciamento de casos têm uma melhor capacidade para avaliar os pacientes e definir as metas a serem alcançadas por eles. Esses pacientes têm melhorado o estado mental, qualidade de vida e consequentemente houve uma diminuição das internações. ${ }^{(28-29)}$

Percebe-se que a semelhança entre o AT e o gerenciamento de casos é tratar do indivíduo em sofrimento mental junto à comunidade e na sua cultura. Recursos como as oficinas e a Copa da Inclusão trazem a comunidade para dentro dos espaços em que o paciente está em tratamento. Assim, de uma maneira ou de outra, o importante é que a pessoa com a doença mental volte a fazer parte da sociedade e sinta-se integrada com a realidade.

Mais recentemente surgiu a estratégia das Residências Terapêuticas, trazendo um avanço na política de saúde mental no contexto da desinstitucionalização, gerando possibilidade de moradia digna e monitoração no desenvolvimento das atividades diárias, objetivando o resgate da autonomia dos sujeitos, da mesma maneira que a reinserção em meios sociais. Dessa forma, fora dos manicômios, os indivíduos ainda têm tutores, são orientados e inseridos num grupo fechado constituído por pacientes em tratamento mental(30), porém com maior convívio comunitário.

O profissional de enfermagem atua em todos os recursos relatados, uma vez que o campo de atuação dese profissional é muito amplo e não totalmente explorado, visando o aprimoramento do cuidado ao doente mental e sus reinserção social.

Os espaços atuais refletem grande diminuição da sobrecarga e do estresse familiar para os envolvidos em tratamento psiquiátrico. O CAPS, grande exemplo deste fenômeno, promove a harmonia familiar e a maior compreensão da problemática da saúde mental, porém no imaginário social ainda há correlação desses espaços com o modelo antigo. Por exemplo, o CAPS e hospital psiquiátrico podem ser confundidos na fala comunitária por falta de conhecimento sobre a natureza do serviço, o que dificulta a adesão ao tratamento(27).

Novamente, é a enfermagem, por sua forte atuação de educação em saúde, que intervém no cenário do imaginário para criar laços com o doente e sua família e promover a adequação terapêutica, a geração da aliança família-doente-equipe de saúde. Esta atuação é uma demonstração da influência dessa categoria na promoção da inclusão(27).

\section{O contexto familiar na reabilitação psicossocial}

A família faz interpretações acerca do comportamento do paciente com transtorno mental de acordo com seus conhecimentos anteriormente acumulados, dando a conotação de estranheza às atitudes tomadas pelo paciente, especialmente em momentos de crise e traduzem o impacto trazido à homeostasia familiar nesse contexto ${ }^{(31)}$. A reflexão sobre quanto maior o conhecimento da família, melhor será sua compreensão e facilitação na rotina com o paciente, trazendo para o enfermeiro e equipe a necessidade de educação familiar para saúde mental.

A família é uma abordagem particular comum nos artigos levantados de 2005 a 2014. Esta é uma parte muito importante na vida dos indivíduos acometidos que são integrantes de uma estrutura familiar, portanto essencial para o tema da reabilitação. A experiência de um CAPS do Rio Grande do Sul sobre a introdução do familiar no ambiente de tratamento como uma filosofia do serviço, demonstra a exigência da instituição, e não uma concessão aos indivíduos com doença mental. A RP tem como pressuposto básico a inclusão e a participação ativa da família, permitindo assim um trabalho conjunto, evitando o abandono do paciente e ajudando aos projetos terapêuticos ${ }^{(32)}$.

Os serviços extra-hospitalares são voltados às famílias. Assim, "oferecer atendimento às famílias para esclarecer a sintomatologia da doença e tornálas aliadas e colaboradoras no tratamento, mantendo o portador desinstitucionalizado para que assim possa ser compreendido em sua singularidade"(32) é uma questão ímpar para dar suporte a esta estrutura familiar. O resultado disto é a alteração no estereótipo da família como responsável pela doença mental, para uma família responsável pelo tratamento e pela reabilitação de seu membro acometido(33). 
A importância do cuidado interdisciplinar aparece também como um benefício a clientes e profissionais, uma vez que as questões que envolvem a saúde mental e a família do indivíduo são complexas e precisam compor com saberes específicos. Os docentes universitários são apontados como os responsáveis pela preparação dos alunos para um trabalho interdisciplinar que envolva as famílias e basicamente "favorecer o crescimento do profissional e da disciplina enquanto ciência"; e ainda a "melhorar as condições de cuidado oferecido à clientela atendida, aumentando a probabilidade da melhora na qualidade de vida e oferecendo um cuidado de maior abrangência"(34). Entretanto, ainda existe o desafio da realização de um trabalho interdiciplinar para a obtenção de um cuidado adequado da família e da pessoa com a doença mental nesse modelo de desinstitucionalização( ${ }^{(34)}$.

A falta de esperança num futuro melhor diminui as perspectivas positivas, paradoxalmente, a família utiliza a crença da melhora para lidar mais satisfatoriamente com seu sofrimento frente à doença mental. Ela não acredita que o hospital psiquiátrico seja um ambiente que cuida de maneira eficiente do seu familiar, pela perda das singularidades do mesmo. O lar é visto como um espaço que contribui para a reabilitação do doente. Mas, a maneira de prestar o cuidado ao indivíduo pode ser tanto um "cuidado eficiente", que o capacitará para lidar com sua vida, quanto um "cuidado dependente", fazendo-o incapaz de assumir suas verdadeiras capacidades ${ }^{(35)}$.

Alguns pressupostos em relação ao contexto familiar envolvendo o papel da enfermagem são: "a bagagem filosófica da enfermeira ajuda o doente e a sua família a encontrar um significado na experiência de doença" e "é de responsabilidade da enfermeira ajudar o doente e sua família a encontrar significado no sofrimento e na doença"(36). Assim, enfermagem e família trabalharão juntos com um objetivo comum que é a recuperação da saúde do familiar(36).

É importante lembrar também que cada família tem suas peculiaridades, mesmo que o problema entre elas seja o mesmo, é necessário conduzir as ações de forma individualizada levando em consideração a realidade de cada uma(3) $^{(36)}$

Enquanto existem registros fenomenológicos sobre familiares cuidadores de doentes mentais e como estes consideram a medicação importante, aproximar a doença e seu contexto com o senso comum, e, mesmo com dificuldades, tentam compreender a patologia e o comportamento do doente ${ }^{(37)}$; outros autores de base quantitativa avaliam e escalonam dimensões da vida do familiar por: A) Assistência na vida cotidiana, B) Supervisão aos comportamentos problemáticos, C) Gastos financeiros, D) Impacto na rotina diária e E) Preocupação com o paciente. Nestes últimos estudos, a maioria das famílias está sobrecarregada nas rotinas do cotidiano. Quando há estratégias para participação dos cuidadores em programas de suporte familiar, onde eles podem expressar sentimentos e dúvidas em relação a patologia, e possibilidade de trocar experiências sobre a doença, ocorre uma diminuição significativa da sobrecarga sentida pelo cuidador(38-39). Aqui, as conclusões em diferentes metodologias fazem ressaltar, talvez, que de maneira geral existe uma adaptação familiar à convivência e ao cuidado, mas é elementar que em setores dimensionados da vida em família existam estressores, e, portanto, de maneira geral defesas psicológicas que atuam nos membros dessa família.

Quanto à inserção do grupo de terapia familiar na rotina dos serviços de saúde mental, observa-se que tem como objetivo corresponsabilizar o familiar e fazer com que seja tanto adequada quanto saudável à convivência entre família e acometido. Os grupos são organizados e se transformam em uma entidade com leis e mecanismos próprios e específicos, no qual todos os integrantes estão reunidos em torno de uma tarefa e um objetivo comum. "O tamanho do grupo não pode exceder o limite que ponha em risco a indispensável preservação da comunicação". Também leva-se em conta "a preservação do espaço (Os dias e o local certo das reuniões), do tempo (Horários, tempo de duração das reuniões, plano de férias, dentre outras) e a combinação de regras e outras variáveis que delimitem e normatizem a atividade grupal proposta"(40).

\section{CAPS e outros espaços como facilitadores da reabilitação psicossocial}

Observamos ao longo da história a consolidação da infraestrutura no tratamento da doença mental na concepção e no estigma da loucura, mantendo relação com a sociedade e determinações políticas ${ }^{(41)}$, configurando a grande dificuldade de transformação do cuidado e atenção ao doente psiquiátrico para os modelos da RP, não somente para teorização das ações, como também dos espaços físicos desta atenção.

A Política Nacional de Saúde Mental dedicase ao objetivo de reduzir o número de leitos para internação em hospitais psiquiátricos, objetivando à expansão de serviços substitutivos, como CAPS, 
residências terapêuticas, ações de saúde mental na atenção básica e leitos em hospitais gerais.

A definição de território onde há atenção à saúde mental retrata um local para além do espaço físico, mas o local que propicia "troca de vivências e de construir uma nova maneira de se conceber o portador de transtorno mental"(42). O resultado categórico da autonomia apoia a funcionalidade do território como espaço no qual a interação entre pacientes e equipe proporciona um papel de subjetivação, da mesma maneira que se fazem responsáveis por gerir a vida e negócios, dinheiro. O espaço, por fim, deixa de ser um local de habitação/permanência e passa a ser um local de habitação de propriedade, tanto do local físico, quanto do espaço interacional, como é o caso das residências ${ }^{(42)}$.

O Programa Nacional de Avaliação dos Serviços Hospitalares (PNASH)/Psiquiatria foi um instrumento criado para comparar a legislação vigente para a saúde mental com a realidade dos hospitais psiquiátricos avaliados. Na avaliação de 16 hospitais em seis estados diferentes, a precariedade assistencial é o que mais chama atenção. Muitas vezes, as exigências mínimas do Ministério da Saúde não são atendidas. Os hospitais que foram avaliados como péssimo (14\%) não tinham nem ao menos um projeto terapêutico a, demonstrando assim a ausência de preocupação com a reinserção social(43).

Em contraposição a esta realidade citada, os CAPS's surgem opondo-se a esta concepção de isolamento do doente e consideram-no como "um sujeito que vive em determinado território, que estabelece relações sociais, que faz parte de uma determinada família e que é portador de um transtorno severo e persistente que tem repercussões em diferentes aspectos de sua vida"(44), mas está buscando resgatar as suas potencialidades, relações e vínculos que podem ter sido perdidos com a doença mental. O foco de atenção dos CAPS's está no paciente e em sua família, com o objetivo de proporcionar uma atenção integral ao indivíduo acometido, envolvendo a sua doença mental e a reabilitação psicossocial(42). $\mathrm{O}$ CAPS é um substitutivo da manifestação de "grandes conflitos e desafios", pois é vivenciado nesse local o fenômeno da crise ${ }^{(45)}$.

Ainda se vê a dicotomia entre os espaços destinados à reabilitação psicossocial. Isto pode ser explicado pelo processo da RP ainda estar em implantação e ser relativamente recente, demonstrando ainda características das antigas práticas asilares juntamente com os novos conceitos de recuperação do indivíduo em seu contexto social. O importante é que estes espaços continuem sendo estudados e avaliados para que o objetivo fundamental da reabilitação da doença mental seja atendido.

\section{Saúde Mental na Atenção Básica}

Em 2004 há a definição de que o trabalho do enfermeiro deve estar focado na atenção primária para promover a saúde mental e desvelar junto ao paciente e familiares o sentido da enfermidade mental. Assim, deve ser a prática de enfermagem baseada em percepção e observação, fazendo interpretações válidas no processo de trabalho, enfatizando o relacionamento terapêutico, considerando como eixo da profissão o modo dinâmico e passível de mudanças $^{(46)}$.

A Estratégia de Saúde da Família (ESF) é um local propício para ações preventivas e detecção precoce de doenças mentais devido ao vínculo dos profissionais com a comunidade. AESF atua seguindo a lógica da desinstitucionalização, pois prioriza o cuidado aos indivíduos na própria unidade de saúde e no domicílio. Sendo assim, constitui-se num bom meio para trabalhar com a saúde mental na atenção básica $^{(47)}$.

Com relação à capacitação de enfermagem na atenção básica focada em Saúde Mental, foi verificada a necessidade de aperfeiçoamento. Este seria destinado à promoção da reinserção social através de práticas de enfermagem que executassem ações conjuntas com outros profissionais, objetivando o suporte familiar e atividades em grupo(47-49), intervenções que assegurariam políticas e práticas antiasilares.

Dentro do CAPS, na construção de rede básica, a estratégia adotada para reinserção do indivíduo em sociedade tem como foco o projeto terapêutico individual (PTI), sendo este um trabalho em equipe multiprofissional que propõe metas estabelecidas em virtude das potencialidades de cada paciente ${ }^{(49)}$. Estas metas são averiguadas em espaços de curto, médio e longo prazo, e levam o indivíduo ao trabalho de recuperação em grupos dentro do próprio CAPS, transitando, em seu tempo, para atividades individuais na vida diária. Um exemplo claro de meta de PTI é o retorno ao trabalho. Em algumas situações o próprio CAPS faz o intermédio entre pacientes e empresas que ofereçam atividades para as quais o indivíduo tem aptidão. Em relação aos profissionais e o PTI, autores afirmam: Os profissionais ficam frente aos desafios de construir outro tipo de cuidado a partir dos projetos terapêuticos individuais, considerando aspectos além da doença, muitas vezes não ensinados e valorizados nos cursos e universidades ${ }^{(49)}$. 
Em relação às atitudes dos profissionais dos CAPS e aos próprios pacientes de saúde mental, ainda é apontado que o ideal, na busca da reinserção social, seria a saída do CAPS para a comunidade trabalhando com os recursos que essas têm para oferecer e, dessa forma, levando esses pacientes a ampliarem suas relações ${ }^{(50)}$.

Dentro da atenção primária, os indivíduos reconhecem o CAPS como uma dimensão significativa de seu cotidiano e relatam que se sentem seguros, que o trabalho no CAPS é bom ${ }^{(51)}$, assim nesse local é exercido um passo vital para a autonomia do acometido, que desfruta de qualidade de vida e produtividade dentro da rede de atenção básica.

\section{Considerações finais}

Considera-se que a produção científica da enfermagem psiquiátrica no contexto da reabilitação psicossocial na literatura nacional, no período estudado, é ampla e variada, abrange o indivíduo acometido pela doença mental, os seus familiares, os recursos utilizados para inclusão social dos pacientes dos serviços de saúde mental, a rede básica de saúde, os espaços para a reabilitação psicológica e social e o próprio profissional de enfermagem como facilitador da recuperação mental.

A assistência de enfermagem deve visualizar de forma holística o ser humano, visto que ainda há a visão da doença mental como um processo exclusivamente biológico, com tratamento baseado somente em medicamentos e com o isolamento social.

A educação continuada dos profissionais da enfermagem objetivando a mudança na reorientação da forma de pensar as práticas em maior consonância com as políticas de saúde mental vigentes, é um bom recurso para que novos hábitos de cuidado sejam adquiridos, assim como a avaliação constante dos serviços que prestam a assistência em saúde mental. A qualidade do atendimento tantos dos hospitais psiquiátricos, quanto dos CAPS devem ser monitorada para a garantia de que o paciente tenha um plano terapêutico que objetive a sua reintegração social.

Em relação ao contexto do paciente psiquiátrico, trabalhar juntamente com sua família é fundamental para que o indivíduo não perca ou recupere sua identidade social. Para tanto, a enfermagem deve ser capaz de orientar as famílias a cuidarem dos seus pacientes, de forma a buscar a independência e inclusão desses indivíduos.

A saúde mental na atenção básica também é um assunto que necessita ser mais discutido e estudado, para fazer com que o cuidado seja eficaz. As ações multidisciplinares podem aumentar o suporte familiar e proporcionar outras atividades aos pacientes, facilitando assim a reabilitação psicossocial nestes dispositivos de atenção à saúde.

Apesar dos estudos abrangerem diversas áreas relativas à saúde mental, a constante renovação dos saberes nessa área é necessária, devido à grande complexidade do ser humano e da doença mental, especialmente quando tratamos das relações para efetivação do cuidado.

\section{Referências}

1. Amarante P. Novos sujeitos, novos direitos: o debate em torno da reforma psiquiátrica. Cad Saúde Pública. [Internet] set 1995 [Acesso 12 nov 2015];11(3):4914. Disponível em: http://www.scielosp.org/scielo. php?script=sci_abstract $\&$ pid=S0102-311X19950003000 24\&lng=pt\&nrm=iso\&tlng=pt

2. Tenório F. A reforma psiquiátrica brasileira, da década de 1980 aos dias atuais: história e conceitos. Hist Cienc Saude Manguinhos. [Internet]. 2002 [Acesso 12 nov 2015];25-59. Disponível em: http://bvsalud.org/portal/ resource/en/his-8911

3. Gonçalves AM, Sena RR de. A reforma psiquiátrica no Brasil: contextualização e reflexos sobre o cuidado com o doente mental na família. Rev. Latino-Am. Enfermagem. [Internet]. abril 2001 [Acesso 12 nov 2015];9(2):4855. Disponível em: http://www.scielo.br/scielo. php?script=sci_arttext\&pid=S0104-11692001000200007 4. Brasil. Ministério da Saúde. Secretaria de Atenção à Saúde. Reforma psiquiátrica e política de saúde mental no Brasil: Conferência Regional de Reforma dos Serviços de Saúde Mental: 15 anos depois de Caracas. MS Brasília; 2005.

5. Antunes SMM de O, Queiroz M de S. Psychiatric reform in a local context in Brazil: a qualitative analysis. Cad Saúde Pública.[Internet]. jan 2007 [Acesso 12 nov 2015];23(1):207-15. Disponível em: http://www.scielo.br/ scielo.php?script=sci_abstract $\&$ pid=S0102-311X200700 0100022\&lng=en\&nrm=iso\&tlng=pt

6. Saraceno B. Libertando identidades: da reabilitação psicossocial à cidadania possível. Belo Horizonte: Te Corá; 1999.

7. Dutra VFD, Rocha RM. O processo de desinstitucionalização psiquiátrica: subsídios para o cuidado integral. Rev Enferm UERJ. [Internet]. set 2011 [Acesso 12 nov 2015];19(3):386-91. Disponível em: http://bases.bireme.br/cgi-bin/wxislind.exe/iah/ online/?IsisScript=iah/iah. $x i s \& s r c=g o o g l e \& b a s e=L I L A C$ S\&lang=p\&nextAction=Ink\&exprSearch=618861\&indexS earch $=I D$ 
8. Silva ALA e, Fonseca RMGS da. Work process in mental health and the psycosocial area. Rev. LatinoAm. Enfermagem. [Internet]. jun 2005 [Acesso 12 nov 2015];13(3):441-9. Disponível em: http://www. scielo.br/scielo.php?script=sci_abstract $\&$ pid $=$ S0104$11692005000300020 \&$ Ing=en\&nrm=iso\&tlng=pt

9. Silveira MR da, Alves M. Nurses in the mental health team: the case of the Mental Health Centers in Belo Horizonte. Rev. Latino-Am. Enfermagem. [Internet]. out 2003 [Acesso 12 nov 2015];11(5):645-51. Disponível em: http://www.scielo.br/scielo.php?script=sci_ abstract\&pid=S0104-11692003000500012\&Ing=en\&nrm $=$ iso\&tlng=pt

10. Mendes KDS, Silveira RC de CP, Galvão CM. Revisão integrativa: método de pesquisa para a incorporação de evidências na saúde e na enfermagem. Texto Contexto Enferm. [Internet]. dez 2008 [Acesso 6 out 2015];17(4):758-64. Disponível em: http:// www.scielo.br/scielo.php?script=sci_arttext\&pid =S0104-07072008000400018

11. Sousa KKB de, Filha F, Oliveira M de, Silva ATMC da. A práxis do enfermeiro no Programa Saúde da Família na Atenção à Saúde Mental. Cogitare Enferm. [Internet]. 2004 [Acesso 11 nov 2015];14-22. Disponível em: http://ojs.c3sl.ufpr.br/ojs2/index.php/cogitare/article/ viewFile/1712/1420

12. Silva ATMC, Barros S. O trabalho de enfermagem no Hospital Dia na perspectiva da reforma psiquiátrica em João Pessoa û Paraíba. Rev Esc Enferm USP. [Internet]. set 2005 [Acesso 11 nov 2015];39(3):310-6. Disponível em: http://bases.bireme.br/cgi-bin/wxislind.exe/iah/ online/?IsisScript=iah/iah. xis \&src=google \&base=BDENF \&lang=p\&nextAction=Ink\&exprSearch=13872\&indexSea rch $=$ ID

13. Terra MG, Ribas DL, Sarturi F, Erdmann AL. Saúde mental: do velho ao novo paradigma - uma reflexão. Esc Anna Nery. [Internet]. dez 2006 [Acesso 11 nov 2015];10(4):711-7. Disponível em: http://www. scielo.br/scielo.php?script=sci_abstract \&pid=S141481452006000400013\&lng=pt\&nrm=iso\&tlng=pt

14. Jorge MSB, Abreu AGC de, Lopes CHA de F, Morais APP, Guimarães JMX. Saúde mental e suas dimensões: análise documental das publicações de periódicos de 2000 a 2005. Rev Gaucha Enferm. [Internet]. 2008 [Acesso 11 nov 2015];468-74. Disponível em: http:// www.seer.ufrgs.br/RevistaGauchadeEnfermagem/ article/viewFile/6776/4079

15. Ministério da Saúde (BR). Secretaria de Atenção à Saúde. Caderno Humaniza SUS: Série B. Textos Básicos em Saúde [Internet]. 2010 [Acesso 11 nov 2015]. Disponível em: http://bvsms.saude.gov.br/bvs/ publicacoes/cadernos_humanizaSUS.pdf
16. Casanova EG, Porto IS, Figueiredo NMA de. O cuidado de enfermagem familiar/exótico na unidade de internação psiquiátrica: do asilar para a reabilitação psicossocial. Esc Anna Nery. [Internet]. dez 2006 [Acesso 11 nov 2015];10(4):635-44. Disponível em: http://www. scielo.br/scielo.php?script=sci_arttext\&nrm=iso\&lng=pt\& tlng=pt\&pid=S1414-81452006000400004

17. Kirschbaum DIR. Concepções produzidas pelos agentes de enfermagem sobre o trabalho em saúde mental com sujeitos psicóticos em um centro de atenção psicossocial. Rev. Latino-Am. Enfermagem. [Internet]. 1 jun 2009;17(3):368-73. Disponível em: http://www. revistas.usp.br/rlae/article/view/4012

18. Guimaräes J, Medeiros SM de. Contribuiçäo ao ensino de saúde mental sob o signo da desinstitucionalizaçäo. Ciênc Saúde Coletiva. [Internet]. 2001 [Acesso 11 nov 2015];97-104. Disponível em: http://www. scielo.br/scielo.php?script=sci_arttext\&pid=S1413$81232001000100008 \&$ Ing=en\&nrm=iso

19. Silva DS, Azevedo DM de. A reforma psiquiátrica na visão de quem cuida: percepções de profissionais do serviço residencial terapêutico. Esc Anna Nery. [Internet]. set 2011 [Acesso 11 nov 2015];15(3):587-94. Disponível em: $\quad$ http://www.scielo.br/scielo.php?script=sci_ arttext\&pid=S1414-81452011000300021\&Ing=en\&nrm=i so\&tlng=pt

20. Dutra VFD. O cuidado oferecido a pessoas que vivenciaram a experiência da desinstitucionalização. Ciênc Cuid Saúde. [Internet]. jun 2011 [Acesso 11 nov 2015];10(2):218-25. Disponível em: http:// www.revenf.bvs.br/scielo.php?script=sci_arttext\&pid =S1677-38612011000200002

21. Oliveira FB de, Fortunato ML. Saúde mental: reconstruindo saberes em enfermagem. Rev Bras Enferm. [Internet]. fev 2003 [Acesso 19 nov 2015];56(1):67-70. Disponível em: http://www.scielo.br/ scielo.php?script=sci_arttext\&nrm=iso\&lng=pt\&tlng=pt\& pid=S0034-71672003000100014

22. Silva ATMC da, Silva CC da, Nóbrega MML da, Filha F, Oliveira M de, Sousa KKB de. Trabalho de enfermagem no programa de saúde da família e sua relação com a desinstitucionalização. Online Braz J Nurs. [Internet]. 2004 [Acesso 11 nov 2015]; Disponível em: http://www. uff.br/nepae/siteantigo/objn303silvaetal.htm

23. Campos $\mathrm{N}$ de L, Kantorskil LP. Música: abrindo novas fronteiras na prática assistencial de enfermagem em saúde mental. Rev Enferm UERJ. [Internet]. março 2008 [Acesso 11 nov 2015];16(1):88-94. Disponível em: http://bases.bireme.br/cgi-bin/wxislind.exe/iah/ online/?IsisScript=iah/iah. $x i s \& s r c=$ google \&base $=$ LILAC S\&lang=p\&nextAction=Ink\&exprSearch $=501522$ \&indexS earch $=I D$ 
24. Pitiá AC de A, Furegato ARF. O Acompanhamento Terapêutico (AT): dispositivo de atenção psicossocial em saúde mental. Interface Comun Saúde Educ. [Internet]. set 2009 [Acesso 11 nov 2015];13(30):67-77. Disponível em: http://www.scielo.br/scielo.php?script=sci_arttext\&pi $\mathrm{d}=\mathrm{S} 1414-32832009000300007$

25. Cassandri JL, SilvaAe, LuisaA. Contribuições da Copa da Inclusão para a consolidação do campo psicossocial. Rev Esc Enferm USP. [Internet]. 2009 [Acesso 11 nov 2015]; Disponível em: http://www.scielo.br/scielo. php? script=sci_arttext\&pid=S0080-62342009000200018 26. Ribeiro LA, Sala ALB, Oliveira AGB de. As oficinas terapêuticas nos centros de atenção psicossocial. Rev Min Enferm. [Internet]. 2008 [Acesso 11 nov 2015];12(4):516-22. Disponível em: http://reme.org.br/ artigo/detalhes/296

27. Lima ICS, Silva LD da C e, Moura MEBMEB, Brito JNP de O, Mesquita GV, Tapety FI. Psychosocial Care Center In View Of Family Caregiver. Rev Pesqui Cuid Fundam Online. [Internet]. 24 abril 2012;0(Supl.):4551. Disponível em: http://seer.unirio.br/index.php/ cuidadofundamental/article/view/1945

28. Reinaldo AM dos S, Luis V, Antonia M. Gerenciamento de casos como estratégia de trabalho para enfermagem psiquiátrica. REME Rev Min Enferm. [Internet]. março 2006 [Acesso 11 nov 2015];10(1):61-8. Disponível em: http://bases.bireme.br/cgi-bin/wxislind.exe/iah/ online/? IsisScript=iah/iah. $x$ is\&src=google\&base=BDENF \&lang=p\&nextAction=Ink\&exprSearch=11475\&indexSea rch $=$ ID

29. Soares MH. Conhecimentos básicos no gerenciamento de casos de saúde mental. SMAD, Rev Eletrônica Saúde Ment Álcool e Drog. [Internet]. ago 2009 [Acesso 11 nov 2015];5(2):1-14. Disponível em: http://pepsic.bvsalud.org/scielo.php?script=sci_ abstract\&pid=S1806-69762009000200010\&lng=pt\&nrm =iso\&tlng=pt

30. Argiles CTL, Kantorski LP, Willrich JQ, Antonacci $\mathrm{MH}$, Coimbra VCC. Redes de sociabilidade: construções a partir do serviço residencial terapêutico. Ciênc Saúde Coletiva. [Internet]. 2013 [Acesso 11 nov 2015];204958. Disponível em: http://www.scielosp.org/scielo. php?script=sci_arttext\&pid=S1413-81232013001500020 31. Colvero $L$ de A, Ide CAC, Rolim MA. Família e doença mental: a difícil convivência com a diferença. Rev Esc Enferm USP. [Internet]. jun 2004 [Acesso 19 nov 2015];38(2):197-205. Disponível em: http:// www.scielo.br/scielo.php?script=sci_arttext\&pid $=$ S0080-62342004000200011

32. Brischiliari A, Waidman MAP. O portador de transtorno mental e a vida em família. Esc Anna Nery. [Internet]. jan 2012 [Acesso 11 nov 2015];16(1):147-56. Disponível em: http://bases.bireme.br/cgi-bin/wxislind. exe/iah/online/? IsisScript=iah/iah.xis\&src=google\&base =BDENF\&lang=p\&nextAction=Ink\&exprSearch=22352\&i ndexSearch $=$ ID

33. Hirdes A, Kantorski LP. A família como um recurso central no processo de reabilitação psicossocial. Rev Enferm UERJ. [Internet]. ago 2005 [Acesso 11 nov 2015];13(2):160-6. Disponível em: http://bases.bireme. br/cgi-bin/wxislind.exe/iah/online/?IsisScript=iah/iah.xis\& src $=$ google $\&$ base $=$ LILACS\&lang $=p \&$ extAction=Ink\&exp rSearch $=413361$ \&indexSearch $=$ ID

34. Waidman MAP, Elsen I. O cuidado interdisciplinar à família do portador de transtorno mental no paradigma da desinstitucionalização. Texto Contexto Enferm. [Internet]. set 2005 [Acesso 11 nov 2015];14(3):341-9. Disponível em: http://bases.bireme.br/cgi-bin/wxislind. exe/iah/online/?lsisScript=iah/iah.xis\&src=google\&base =BDENF\&lang=p\&nextAction=Ink\&exprSearch=14270\&i ndexSearch=ID

35. Oliveira AMN de, Lunardi, Silva MRS da. Repensando o modo de cuidar do ser portador de doença mental e sua família a partir de Heidegger. Cogitare Enferm. [Internet]. abril 2005 [Acesso 11 nov 2015];10(1):9-15. Disponível em: http://bases.bireme.br/cgi-bin/wxislind. exe/iah/online/? IsisScript=iah/iah. $x i s \& s r c=g o o g l e \& b a s e$ =LILACS\&lang=p\&nextAction=Ink\&exprSearch=436016 \&indexSearch=ID

36. Waidman MAP, Elsen I, Marcon SS. Possibilidades e limites da teoria de Joyce Travelbee para a construção de uma metodologia de cuidado à família. Rev Eletrônica Enferm. [Internet]. 28 ago 2009 [Acesso 11 nov 2015];8(2). Disponível em: http://h200137217135.ufg.br/ index.php/fen/article/view/7043

37. Cardoso L, Galera SAF. O cuidado em saúde mental na atualidade. Rev Esc Enferm USP [Internet]. jun 2011 [Acesso 11 nov 2015];45(3):687-91. Disponível em: http://www.scielo.br/scielo.php?script=sci_arttext\&pid =S0080-62342011000300020

38. Gomes MS, Mello R. Sobrecarga gerada pelo convívio com o portador de esquizofrenia: enfermagem construindo o cuidado à família. SMAD, Rev Eletrônica Saúde Ment Alcool Drog. [Internet]. 2012 [Acesso 11 nov 2015];2-8. Disponível em: http:// pepsic.bvsalud.org/scielo.php?script=sci_arttext\&pid =S1806-69762012000100002

39. Loukissa DA. Family burden in chronic mental illness: a review of research studies. J Adv Nurs, [Internet]. 1 fev 1995 [Acesso 11 nov 2015];21(2):24855. Disponível em: http://onlinelibrary.wiley.com/ doi/10.1111/j.1365-2648.1995.tb02521.x/abstract

40. Ribeiro JP, Coimbra VCC, Borges AM. Grupo de familiares de um centro de atenção psicossocial: experiências de seus usuários. Rev Enferm UFSM. [Internet]. ago 2012 [Acesso 11 nov 2015];2(2):375-85. 
Disponível em: http://bases.bireme.br/cgi-bin/wxislind. exe/iah/online/?IsisScript=iah/iah.xis\&src=google\&base =BDENF\&lang=p\&nextAction=Ink\&exprSearch=24676\& $\mathrm{i}$ ndexSearch $=$ ID

41. Sadigursky D, Tavares JL. Algumas considerações sobre o processo de desinstitucionalização. Rev. LatinoAm. Enfermagem. [Internet]. 1 abril 1998;6(2):23-7. Disponível em: http://www.revistas.usp.br/rlae/article/ view/1288

42. Matos BG de, Moreira LH de O. Servico residencial terapeutico: o olhar do usuario. Esc Anna Nery. [Internet]. set 2013 [Acesso 11 nov 2015];17(4):668-76. Disponível em: $\quad$ http://www.scielo.br/scielo.php?script=sci_ arttext\&pid=S1414-81452013000400668\&lng=en\&nrm= iso\&tlng=en, http://www.scielo.br/scielo.php?script=sci_ arttext\&pid=S1414-81452013000400668\&lng=en\&nrm= iso\&tlng $=p t$

43. Loyola CMD, Pôrto K da F, Rocha K da S. Implicações do Programa Nacional de Avaliação do Sistema Hospitalar Psiquiátrico para a enfermagem psiquiátrica. Rev Enferm UERJ. [Internet]. março 2009 [Acesso 11 nov 2015];17(1). Disponível em: http://bases.bireme.br/ cgi-bin/wxislind.exe/iah/online/?/sisScript=iah/iah.xis\&sr $c=$ google\&base $=$ LILACS\&lang=p\&nextAction=Ink\&expr Search $=513352 \&$ indexSearch $=$ ID

44. Kantorski LP, Souza J de, Willrich JQ, Mielke FB. O cuidado em saúde mental: um olhar a partir de documentos e da observação participante. Rev Enferm UERJ. [Internet]. set 2006 [Acesso 11 nov 2015];14(3):366-71. Disponível em: http://www. scielo.br/scielo.php?script=sci_arttext $\&$ pid=S010435522006000300007\&lng=pt\&nrm=iso\&tlng=pt

45. Willrich JQ, Kantorski LP, Chiavagatti FG, Cortes JM, Pinheiro GW. Periculosidade versus cidadania: os sentidos da atenção à crise nas práticas discursivas dos profissionais de um Centro de Atenção Psicossocial. Physis Rio J. [Internet]. 2011 [Acesso 11 nov 2015];21(1):47-64. Disponível em: http://www. scielo.br/scielo.php?script=sci_arttext $\&$ pid=S010373312011000100004\&lng=en\&nrm=iso\&tlng=pt

46. Villela S de C, Scatena MCM. A enfermagem e o cuidar na área de saúde mental: [revisão]. Rev Bras Enferm. [Internet]. 2004 [Acesso 11 nov 2015];738-41. Disponível em: http://www.scielo.br/scielo.php?script=sci_arttext\&pi $d=$ S0034-71672004000600022

47. Lemos SS, Lemos M, Souza M da GG. O preparo do enfermeiro da atenção básica para a saúde mental. Arq Ciênc Saúde. [Internet]. dez de 2007 [Acesso 11 nov 2015];14(4):198-202. Disponível em: http://bases. bireme.br/cgi-bin/wxislind.exe/iah/online/? IsisScript=iah/ iah. $x$ is \&src=google\&base=LILACS\&lang=p\&nextAction= Ink\&exprSearch=514617\&indexSearch=ID
48. Brêda $M Z$, Rosa $W$ de $A G$, Pereira MAO, Scatena MCM. Duas estratégias e desafios comuns: a reabilitação psicossocial e a saúde da família. Rev. Latino-Am. Enfermagem.[Internet]. 2005 [Acesso 11 nov 2015];450-2. Disponível em: http://www.scielo.br/scielo. php?script=sci_arttext\&pid=S0104-11692005000300021 49. Mororó MEML, Colvero L de A, Machado AL. Os desafios da integralidade em um Centro de Atenção Psicossocial e a produção de projetos terapêuticos. Rev Esc Enferm USP. [Internet]. out 2011 [Acesso 11 nov 2015];45(5):1171-6. Disponível em: http://www. scielo.br/scielo.php?script=sci_arttext $\&$ pid $=$ S008062342011000500020\&lng=pt\&nrm=iso\&tlng=en

50. Mielke FB, Olschowsky A, Pinho LB de, Wetzel C, Kantorski LP. Avaliação qualitativa da relação de atores sociais com a loucura em um serviço substitutivo de saúde mental. Rev Bras Enferm [Internet]. jun 2012 [Acesso 11 nov 2015];65(3):501-7. Disponível em: http://www.scielo.br/scielo.php?script=sci_arttext\&pid =S0034-71672012000300016

51. Nasi C, Schneider JF. O Centro de Atenção Psicossocial no cotidiano dos seus usuários. Rev Esc Enferm USP. [Internet]. out 2011 [Acesso 11 nov 2015];45(5):1157-63. Disponível em: http:// www.scielo.br/scielo.php?script=sci_arttext\&pid $=$ S0080-62342011000500018 